\title{
Polarization selection of radar target using the principal component method
}

\author{
A.B. Borzov, L.V. Labunetc, K.P. Likhoedenko, I.V. Muratov, G.L. Pavlov ${ }^{*}$, V.B. Suchkov, \\ and $V . K$. Khokhlov \\ Bauman Moscow State Technical University, 105005, Moscow, 2-nd Baumanskaya 5, Russia
}

\begin{abstract}
The results of polarization selection of radar targets using the method of principal components according to the results of modeling and field experiments are presented. Target Detection Algorithms Received
\end{abstract}

\section{Introduction}

The use of polarization characteristics makes it possible to solve a number of problems associated with the selection of anthropogenic objects against the background of interfering reflections of natural formations, as well as to solve the problem of identifying and classifying targets that have a simple shape (rotation bodies, corner reflectors, etc.). The polarization scattering matrix (MR) of a "point" object is used as a model corresponding to the process of displaying the radiophysical properties of simple targets in the polarization parameters of a scattered wave.

We note that neither the deterministic nor the statistical theory of polarization of radio waves scattered by stable and fluctuating point objects, described both in the fundamental works [1] and in the original works of other researchers [2], does not provide algorithms for recognizing targets and backgrounds and does not allow quantitative evaluations of these effects.

The material of the report is based on more than 40 years of experience in developing a methodology (a set of methods) for studying the radar scattering fields of radio waves of the quasi-optical (from decimetre and above) range from almost all classes of objects of technology, both individually and under different background-target scenes forming at a given interval observation radar scene.

\section{Objects of research, simulation and experiment results}

The objects of research are a radar, which allows to obtain a complete polarization matrix and a model of a signal reflected from various targets.

To develop algorithms and verify them during the work, we used a mathematical model for the scattering of radio waves of the quasi-optical range by radar scenes [3-8], which allows one to take into account complex radiophysical effects in the interaction of radar signals and typical targets in complex scenes and scenes, in particular such as diffraction by

* Corresponding author: wave@sm.bmstu.ru 
sharp edges, wave re-reflection, transformation and enrichment of the spectrum of the probe signal, wave depolarization, the rough nature of the underlying surface, vegetation, anthropogenic objects you etc.

Using this mathematical model, several radar scenes were synthesized. In particular, a scene with an object (target) on the background of the underlying surface, the underlying surface itself and the test (reference) target in the form of a dihedral angular reflector in two positions.

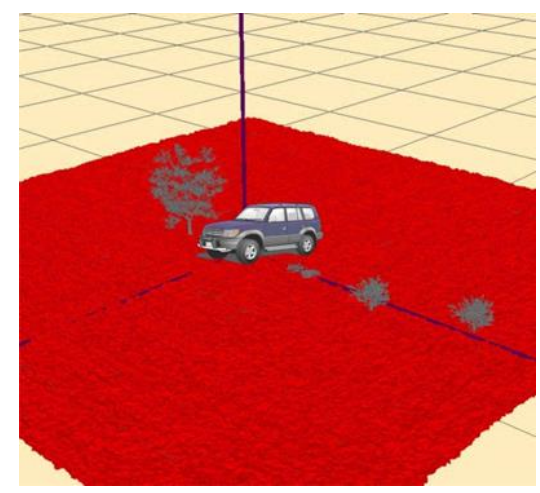

Fig. 1. Radar scene with a target.

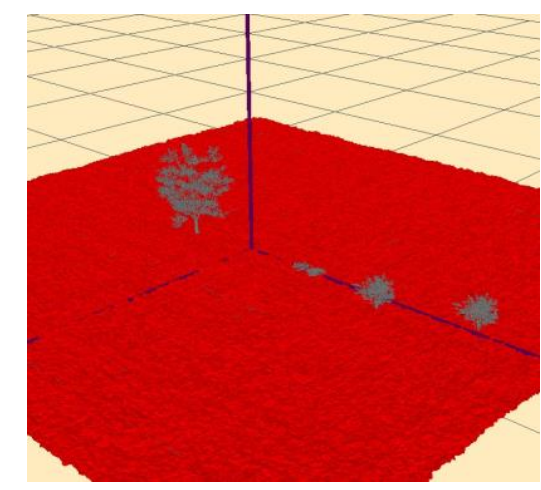

Fig. 2. A radar scene without a target.
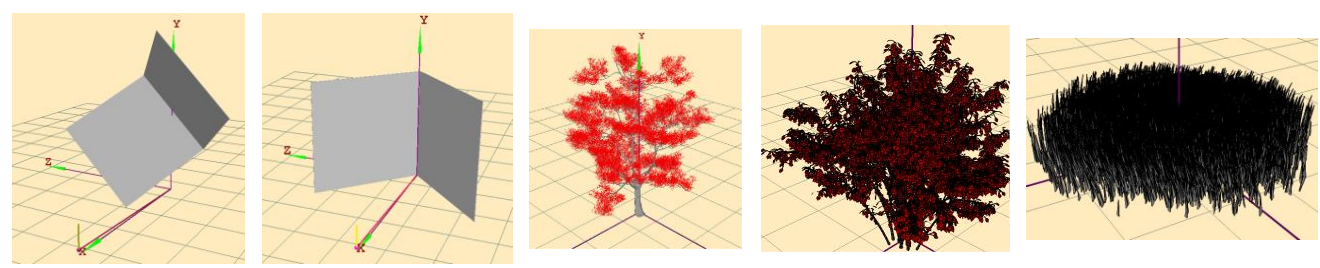

Fig. 3. Reference targets and types of background formations.

For a typical radar scene with a target (Fig. 1) as a result of modeling, for each range gate, the following are obtained:

1. Complete polarization matrices of the form

$$
\|S\|=\left\|\begin{array}{cc}
\sigma_{H H} & \sigma_{H V} \\
\sigma_{V H} & \sigma_{V V}
\end{array}\right\|,
$$

where $\sigma_{u n}$ - are the RCS values values in the resolution element with the corresponding polarization of the radiation $(\mathrm{u})$ and reception $(\mathrm{n})$ taking into account complex diffraction effects (sharp edges, moving angles, reflection, ...) [3-8].

2. The matrix of signal amplitudes in two quadratures for each polarization state

$$
\|A\|=\left\|\begin{array}{ll}
\operatorname{Re} \dot{A}_{H H}+\operatorname{Im} \dot{A}_{H H} & \operatorname{Re} \dot{A}_{H V}+\operatorname{Im} \dot{A}_{H V} \\
\operatorname{Re} \dot{A}_{V H}+\operatorname{Im} \dot{A}_{V H} & \operatorname{Re} \dot{A}_{V H}+\operatorname{Im} \dot{A}_{V H}
\end{array}\right\|,
$$

where $A_{u n}$ is the complex amplitude of the signal in the resolution element with the corresponding polarization of the radiation $(\mathrm{u})$ and reception $(n)$ taking into account the reflections.

The calculation results for the model are presented in tabular form. Rows of tables correspond to range gates. Columns are the values of the polarization state. 
Table 1. The results of the calculation of the RCS values in the scene with the target.

\begin{tabular}{|c|c|c|c|c|c|}
\hline range gates & $\mathrm{HH}$ & $\mathrm{HV}$ & VV & VH & object \\
\hline 1 & $2,322 \mathrm{E}-05$ & $1,770 \mathrm{E}-06$ & $2,182 \mathrm{E}-05$ & $2,463 \mathrm{E}-06$ & \multirow{2}{*}{ Grass } \\
\hline 2 & $2,229 \mathrm{E}-04$ & $1,413 \mathrm{E}-05$ & $1,595 \mathrm{E}-05$ & $1,414 \mathrm{E}-05$ & \\
\hline 5 & $2407 \mathrm{~F}_{01}$ & $6728 \mathrm{E} 04$ & $1838 \mathrm{~F} 01$ & $6056 \mathrm{E} 04$ & \multirow{3}{*}{ Shrub } \\
\hline 6 & $1.351 \mathrm{E}-01$ & $5.805 \mathrm{E}-04$ & $1.158 \mathrm{E}-01$ & $5.178 \mathrm{E}-04$ & \\
\hline 7 & $1,934 \mathrm{E}-04$ & $7,064 \mathrm{E}-06$ & $1,460 \mathrm{E}-04$ & $7,228 \mathrm{E}-06$ & \\
\hline 10 & $1,988 \mathrm{E}-01$ & $3,320 \mathrm{E}-04$ & $1,406 \mathrm{E}-01$ & $3,262 \mathrm{E}-04$ & Shrub \\
\hline & & & & & \\
\hline 20 & $2,599 \mathrm{E}+00$ & $9,658 \mathrm{E}-02$ & $5,059 \mathrm{E}+00$ & $9,466 \mathrm{E}-02$ & \multirow{2}{*}{$\begin{array}{c}\text { Target } \\
\text { (vehicle) }\end{array}$} \\
\hline 21 & $1,247 \mathrm{E}+01$ & $6,666 \mathrm{E}-02$ & $1,483 \mathrm{E}+01$ & $6,771 \mathrm{E}-02$ & \\
\hline 22 & $6,305 \mathrm{E}-01$ & $4,293 \mathrm{E}-04$ & $4,393 \mathrm{E}-01$ & $3,899 \mathrm{E}-04$ & \multirow{4}{*}{ Tree } \\
\hline 23 & $2,309 \mathrm{E}-01$ & $4,760 \mathrm{E}-04$ & $2,041 \mathrm{E}-01$ & $7,959 \mathrm{E}-04$ & \\
\hline 24 & $2,163 \mathrm{E}-01$ & $6,991 \mathrm{E}-04$ & $2,923 \mathrm{E}-01$ & $7,981 \mathrm{E}-04$ & \\
\hline 25 & $1,854 \mathrm{E}-01$ & $1,321 \mathrm{E}-03$ & $1,689 \mathrm{E}-01$ & $2,214 \mathrm{E}-03$ & \\
\hline 38 & $2,950 \mathrm{E}-05$ & $8,364 \mathrm{E}-08$ & $7,121 \mathrm{E}-06$ & $8,413 \mathrm{E}-08$ & \multirow{3}{*}{ Grass } \\
\hline 39 & $4,864 \mathrm{E}-05$ & $4,298 \mathrm{E}-05$ & $1,474 \mathrm{E}-06$ & $4,268 \mathrm{E}-05$ & \\
\hline 40 & $6,052 \mathrm{E}-05$ & $1,053 \mathrm{E}-05$ & $4,767 \mathrm{E}-05$ & $1,060 \mathrm{E}-05$ & \\
\hline
\end{tabular}

The main attention is focused on algorithms for selecting signals in the radar from various classes of targets according to their polarization properties (parameters and characteristics), which determines the sequence of presentation.

The basis is the method of principal components with factorization.

The approach presented in this paper to solving the problems of polarization selection using the principal component method is original. This approach allows one to take into account the correlation properties not only in the scattering matrix within one range gate, but also to take into account the correlations between adjacent range gates, which allows one to separate targets as regular objects and underlying surfaces as irregular. In general, this approach develops the ideas presented in the works, in particular, Cloud, Potier, Freeman $[9,10,11]$.

In accordance with the principal component method for the input data matrix (Table 1), we obtain a correlation matrix

$$
\mathbf{K}=\mathbf{X}^{\mathbf{T}} \mathbf{X}
$$

This matrix: Ermitov, Teplice and positive definite, that is, there always exists an inverse matrix.

Table 2. The correlation matrix for the scene with the target.

\begin{tabular}{|c|c|c|c|c|}
\hline Channel & HH & HV & VV & VH \\
\hline HH & 1,000 & 0,660 & 0,991 & 0,669 \\
\hline HV & 0,660 & 1,000 & 0,744 & 1,000 \\
\hline VV & 0,991 & 0,744 & 1,000 & 0,752 \\
\hline VH & 0,669 & 1,000 & 0,752 & 1,000 \\
\hline
\end{tabular}

Eigenvalues of this matrix: 3,$408794 ; 0.589475 ; 0.001677 ; 0.000054$; make it possible to form a matrix of eigenvectors presented in table 3 for four different factors of structural analysis of the data formed by the vector of eigenvalues, which is essentially a matrix of the transition from the polarization basis to the factor one [12]. 
Table 3. Eigenvectors of the correlation matrix in the scene with the target.

\begin{tabular}{|c|c|r|r|r|}
\hline Channel & F 1 & F 2 & F 3 & F 4 \\
\hline HH & $-0,486653$ & 0,570703 & 0,644747 & $-0,147541$ \\
\hline HV & $-0,499660$ & $-0,502621$ & $-0,092297$ & $-0,699423$ \\
\hline VV & $-0,511333$ & 0,427714 & $-0,729269$ & 0,154161 \\
\hline VH & $-0,502042$ & $-0,488601$ & 0,209640 & 0,682109 \\
\hline
\end{tabular}

The next step is to calculate the contribution of the observations (polarization matrix by range gates) to the corresponding factors. In fact, we calculate the projection of data (signals in the channels) onto new coordinate axes - factors [12].

The contributions of observations in tabular form are given in table 4 .

Table 4. Observation contributions for the scene with the target.

\begin{tabular}{|c|c|c|c|c|c|}
\hline range gates & $\mathrm{HH}$ & $\mathrm{HV}$ & VV & $\mathrm{VH}$ & object \\
\hline 1 & 0,20456 & 0,012264 & 0,040479 & 0,016035 & \multirow{2}{*}{ Grass } \\
\hline 2 & 0,20404 & 0,012009 & 0,038402 & 0,018782 & \\
\hline 5 & 0,11413 & 0,067164 & 0,89335 & 5.059915 & \multirow{3}{*}{ Shrub } \\
\hline 6 & 0,14318 & 0,030817 & 0,071877 & 1,653883 & \\
\hline 7 & 0,2043 & 0,012178 & 0,039783 & 0,017556 & \\
\hline 10 & 0,13707 & 0,060473 & 0,563547 & 2,257989 & Shrub \\
\hline 20 & 27.7585 & 43,870018 & 17,615773 & 3.823521 & \multirow{2}{*}{$\begin{array}{c}\text { Target } \\
\text { (vehicle) }\end{array}$} \\
\hline 21 & 61,7775 & 34,040739 & 0,872087 & 0,069641 & \\
\hline 22 & 0,04894 & 0,364469 & 7,493782 & 21,45984 & \multirow{4}{*}{ Tree } \\
\hline 23 & 0,11441 & 0,065468 & 0,345748 & 1,731157 & \\
\hline 24 & 0,10264 & 0,071408 & 0,441829 & 1,084868 & \\
\hline 25 & 0,09229 & 0,009293 & 0,745571 & 33,7853 & \\
\hline 38 & 0,20464 & 0,012311 & 0,040656 & 0,017414 & \multirow{3}{*}{ Grass } \\
\hline 39 & 0,20292 & 0,011329 & 0,036596 & 0,019928 & \\
\hline 40 & 0,20421 & 0,012073 & 0,039686 & 0,017688 & \\
\hline
\end{tabular}

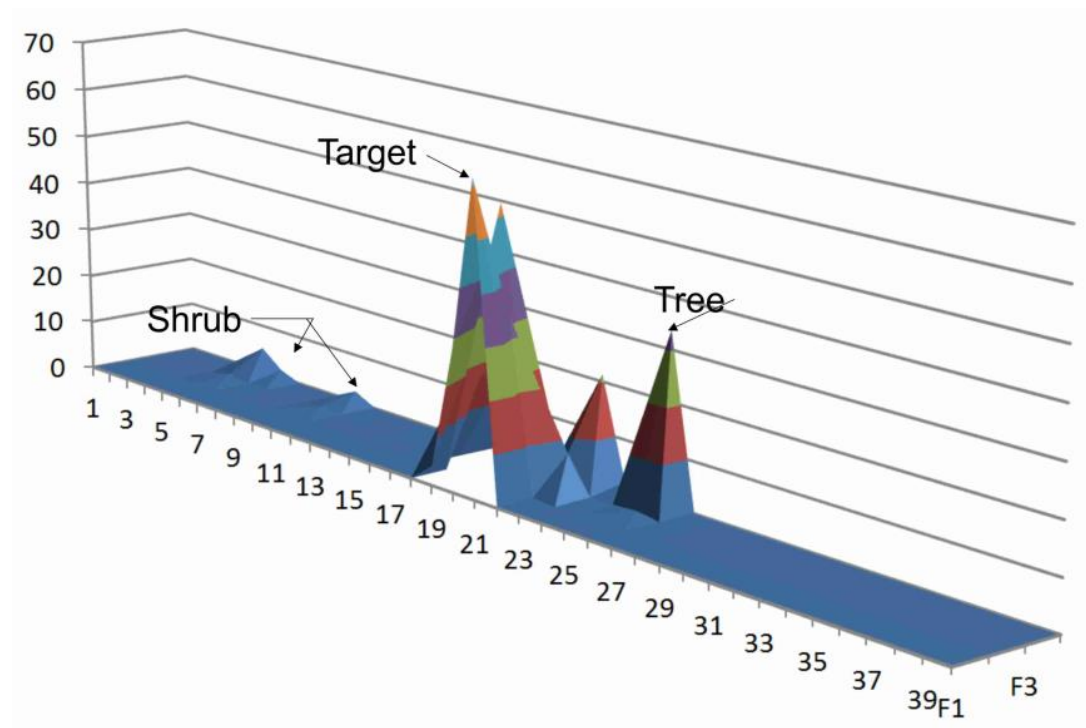

Fig. 4. Observation contributions for the scene with the target. 
The scene of fig. 2, without a target, that is, only a meadow, as the clutter, shrubs and trees. The results of the calculation of the signal in terms of RCS (power, energy) are presented in table 5 .

Table 5. The results of the calculation of the RCS values in the scene without a target, only the background.

\begin{tabular}{|c|c|c|c|c|c|}
\hline range gates & $\mathrm{HH}$ & $\mathrm{HV}$ & $\mathrm{VV}$ & $\mathrm{VH}$ & object \\
\hline 1 & $7,54 \mathrm{E}-02$ & $4,26 \mathrm{E}-02$ & $2,24 \mathrm{E}-02$ & $4,26 \mathrm{E}-02$ & \multirow{2}{*}{ Grass } \\
\hline 2 & $1,48 \mathrm{E}+02$ & $4,72 \mathrm{E}-01$ & $8,80 \mathrm{E}+00$ & $3,76 \mathrm{E}-01$ & \\
\hline 5 & $1,67 \mathrm{E}+01$ & $6,60 \mathrm{E}-01$ & $5,41 \mathrm{E}-01$ & $6,50 \mathrm{E}-01$ & \multirow{3}{*}{ Shrub } \\
\hline 6 & $2,48 \mathrm{E}+03$ & $1,13 \mathrm{E}+01$ & $2,18 \mathrm{E}+03$ & $1,05 \mathrm{E}+01$ & \\
\hline 7 & $1,62 \mathrm{E}+03$ & $1,06 \mathrm{E}+01$ & $1,52 \mathrm{E}+03$ & $9,58 \mathrm{E}+00$ & \\
\hline 10 & $5,43 \mathrm{E}+00$ & $4,98 \mathrm{E}-01$ & $3,39 \mathrm{E}+00$ & $5,41 \mathrm{E}-01$ & Shrub \\
\hline 20 & $5,95 \mathrm{E}+00$ & $2,48 \mathrm{E}+00$ & $2,81 \mathrm{E}-01$ & $2,54 \mathrm{E}+00$ & \\
\hline 21 & $8,80 \mathrm{E}+00$ & $2,63 \mathrm{E}+00$ & $2,10 \mathrm{E}+00$ & $2,66 \mathrm{E}+00$ & \\
\hline 22 & $1,13 \mathrm{E}+01$ & $4,26 \mathrm{E}-01$ & $1,84 \mathrm{E}+00$ & $4,44 \mathrm{E}-01$ & \multirow{4}{*}{ Tree } \\
\hline 23 & $4,09 \mathrm{E}+00$ & $5,51 \mathrm{E}+00$ & $2,45 \mathrm{E}+00$ & $5,63 \mathrm{E}+00$ & \\
\hline 24 & $8,47 \mathrm{E}+02$ & $5,78 \mathrm{E}+01$ & $1,13 \mathrm{E}+03$ & $5,60 \mathrm{E}+01$ & \\
\hline 25 & $7,75 \mathrm{E}+02$ & $5,66 \mathrm{E}+00$ & $5,70 \mathrm{E}+02$ & $8,92 \mathrm{E}+00$ & \\
\hline 39 & $5,01 \mathrm{E}+00$ & $5,27 \mathrm{E}-01$ & $4,93 \mathrm{E}-01$ & $5,29 \mathrm{E}-01$ & \multirow{2}{*}{ Grass } \\
\hline 40 & $1,49 \mathrm{E}+01$ & $2,18 \mathrm{E}+00$ & $6,72 \mathrm{E}-01$ & $2,20 \mathrm{E}+00$ & \\
\hline
\end{tabular}

Table 6. The correlation matrix for the scene without a target.

\begin{tabular}{|c|c|c|c|c|}
\hline Channel & HH & HV & VV & VH \\
\hline HH & 1,000 & 0,215 & 0,994 & 0,204 \\
\hline HV & 0,215 & 1,000 & 0,300 & 0,998 \\
\hline VV & 0,994 & 0,300 & 1,000 & 0,288 \\
\hline VH & 0,204 & 0,998 & 0,288 & 1,000 \\
\hline
\end{tabular}

Eigenvalues of this matrix: 2,$500798 ; 1.49511 ; 0.002731 ; 0.001361$.

Table 7. Eigenvectors of the correlation matrix in a scene without a target

\begin{tabular}{|c|c|c|c|c|}
\hline Channel & F 1 & F 2 & F 3 & F 4 \\
\hline HH & $-0,480962$ & 0,530159 & 0,667649 & $-0,204576$ \\
\hline HV & $-0,504038$ & $-0,493371$ & $-0,181318$ & $-0,685313$ \\
\hline VV & $-0,514926$ & 0,473768 & $-0,680450$ & 0,217676 \\
\hline VH & $-0,499472$ & $-0,501059$ & 0,241572 & 0,664162 \\
\hline
\end{tabular}

Table 8. Observation contributions for the scene without a target.

\begin{tabular}{|c|c|c|c|c|c|}
\hline range gates & $\mathrm{HH}$ & $\mathrm{HV}$ & VV & VH & object \\
\hline 1 & 0,639742 & 0,004037 & 0,352959 & 0,002514 & \multirow{2}{*}{ Grass } \\
\hline 2 & 0,454711 & 0,020899 & 7,207422 & 2,956406 & \\
\hline 5 & 0,536962 & 0,000016 & 0,010588 & 0,056038 & \multirow{3}{*}{ Shrub } \\
\hline 6 & 10,009957 & 6,785117 & 3,728194 & 0,010956 & \\
\hline 7 & 4,555731 & 2,106274 & 15,505441 & 0,017406 & \\
\hline 10 & 0,562158 & 0,000181 & 0,199602 & 0,002939 & Shrub \\
\hline 20 & 0,319635 & 0,051809 & 0,001925 & 0,00527 & \\
\hline 21 & 0,302571 & 0,057435 & 0,004843 & 0,000008 & \\
\hline 22 & 0,570748 & 0,000732 & 0,085714 & 0,008084 & \multirow{4}{*}{ Tree } \\
\hline 23 & 0,077766 & 0,352797 & 0,306757 & 0,087067 & \\
\hline 24 & 33,58448 & 26,180753 & 7,184273 & 1,487977 & \\
\hline 25 & 0,523688 & 0,088405 & 24,631613 & 66,160966 & \\
\hline 39 & 0,564409 & 0,000094 & 0,157274 & 0,007513 & \multirow[b]{2}{*}{ Grass } \\
\hline 40 & 0,348246 & 0,032922 & 0,025774 & 0,015504 & \\
\hline
\end{tabular}




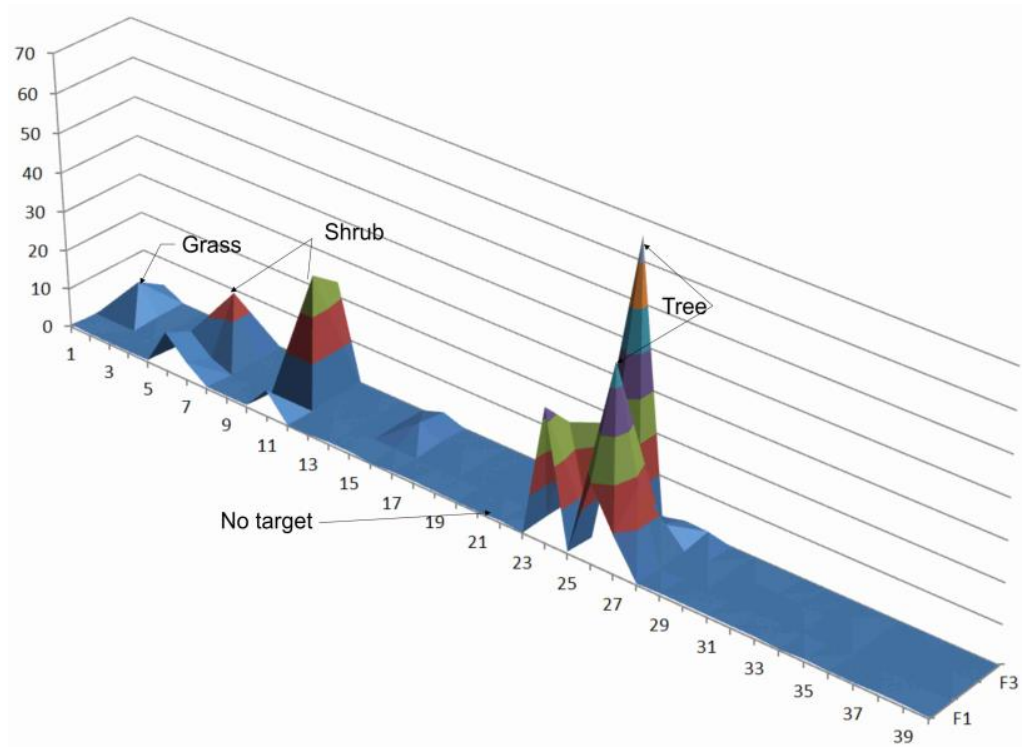

Fig. 4. Observation contributions for the scene without a target.

The simulation results were confirmed experimentally.

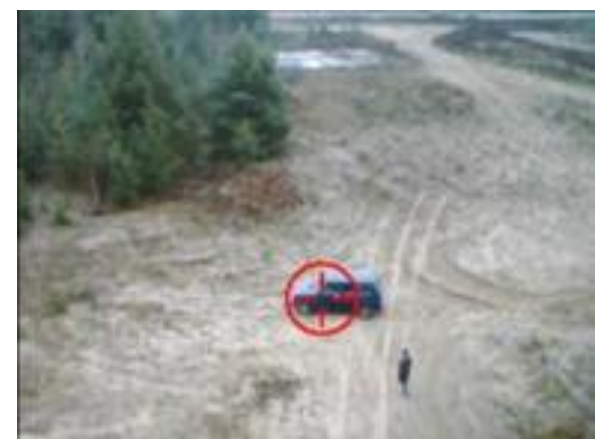

Fig. 5. Experiment. Conditions.

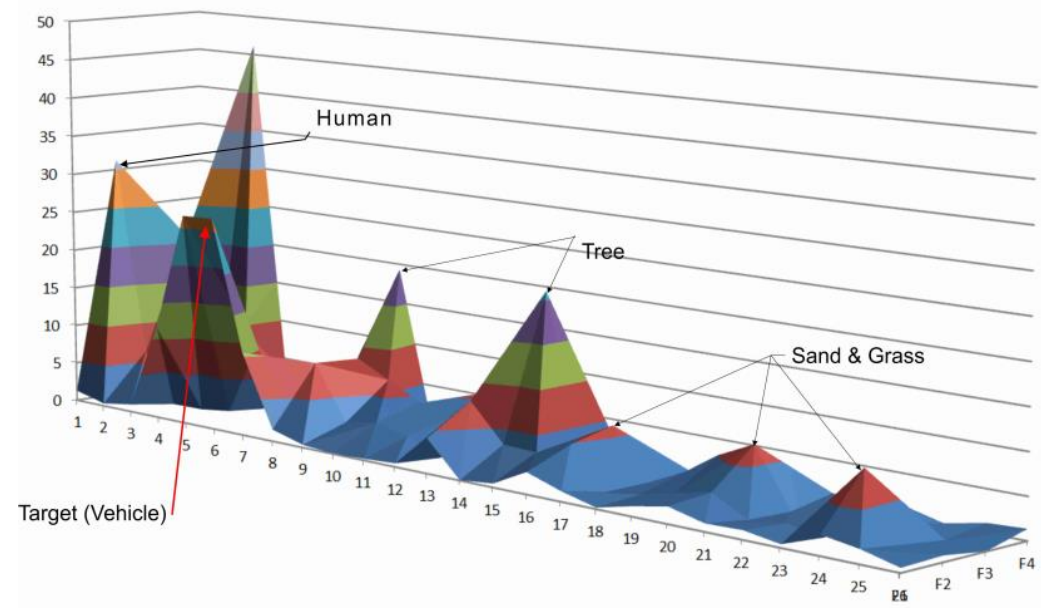

Fig. 6. Contributions of observations in the experiment. 


\section{Target detection algorithm}

An analysis of the results allows us to note the following:

- factors 1 and 2 - can be interpreted as the general energy of the signals;

- factor 3 - the influence of the main polarizations;

- factor 4 - the effect of cross polarization.

In this case, the target is concentrated on factor coordinates 1 and 2, while background formations such as grass, shrubs and trees are concentrated in factors 3 and 4 .

Target detection and its selection against the background of natural formations using the contribution matrix is performed as follows.

The signal level in the first factor (values in the first column) is determined by the total energy of the reflected signal, therefore, the search and detection of the target is primarily performed by the signal level in the first column. To recognize the target, the signals of the remaining columns are used.

A regular target (consisting of a set of reflectors) gives a response in the first and second factors, that is, the values of the first and second columns for the corresponding range strobe (matrix row) exceed the detection thresholds. At the same time, the values for the third and fourth factors (in the third and fourth columns, respectively) do not exceed the threshold level.

Irregular targets that contain many disordered elements, such as grass, shallow vegetation, and trees, are mainly grouped in the third and fourth factors. In addition, at high resolution $(1 \mathrm{~m})$, a mirror reflection of the target from the surface is traced.

In the case when it is required to detect the target on the surface and not to classify the surface itself, the detection algorithm can be represented as

$$
\text { If } v k_{i, 1}>P 1 \text { and } v k_{i, 1}>v k_{i, 2} \text { and }\left(v k_{i, 3}<P 2 \text { или } v k_{i, 4}<P 2\right) \text {. }
$$

Thresholds $\mathrm{P} 1$ and $\mathrm{P} 2$, rationally, should be selected according to the results of experiments or using an adaptive algorithm with a constant level of false alarms. In a first approximation, the following values can be taken as a basis

$$
\begin{gathered}
P 1=\frac{1}{M} \sum_{k=1}^{M} v k_{k, 1}+\sqrt{\frac{1}{M-1} \sum_{k=1}^{M}\left(v k_{k, 1}-\frac{1}{M} \sum_{k=1}^{M} v k_{k, 1}\right)^{2}}, \\
P 2=\frac{v k_{i, 1}}{2 M} .
\end{gathered}
$$

The computational complexity of the above algorithm can be estimated on the basis of the most time-consuming operation - the calculation of eigenvalues and eigenvectors. When using the QR algorithm, even not optimized, the computational complexity will not exceed $O\left(\mathrm{~N}^{3}\right)$. That is, a $4 \times 4$ matrix will require no more than 64 operations.

\section{Conclusion}

An analysis of the presented modeling results and experimental data on detecting a "vehicle" type target against a typical plot in the form of a plot of meadows, shrubs and a tree allows us to make the main conclusion: Realization in the radar of the full polarization reception mode in combination with high resolution in range and the application of the principal components method fundamentally allow you to divide the space of target and backgrounds. Thus, the presented method of target selection allows you to reliably detect man made objects in a complex background environment. 


\section{References}

1. D. Giuli, Proceedings of the IEEE.- v. 74, № 2, (1986)

2. R.V. Ostrovityanov, F.A. Basalov Statistic theory of long-target radar. - M.: Radio and communication [in Russian] (1982)

3. V.V. Akhiyarov, Y.V. Karakulin, A.B. Borzov, G.M. Seregin, K.P. Likhoedenko, V.B. Suchkov ACM International Conference Proceeding Series, №a67 (2018)

4. A.B. Borzov and al. Issues of modeling autonomous information systems of near location. ISBN 978-5-7013-0135-9 [in Russian] (2010)

5. A.B. Borzov, V.B. Suchkov, B.I. Shakhtarin, Y.A. Sidorkina, J. Commun. Technol. Electron. 59 (12), pp. 1356-1368 (2014)

6. A.B. Borzov, G.L. Pavlov, V.B. Suchkov. Nelinejny mir, V. 8. No. 1. Pp. 12-21. [in Russian] (2010)

7. A.B. Borzov, G.L. Pavlov, V.B. Suchkov, K.P. Likhoedenko, I.V. Muratov. Elektromagnitnye volny i elektronnye sistemy. V. 15. No 7. Pp. 27-40 [in Russian] (2010)

8. V.V. Akhiyarov, A.B. Borzov, V.B. Suchkov, B.I. Shakhtarin, Y.A. Sidorkina. J. Commun. Technol. Electron., 60 (12), pp. 1297-1304 (2015)

9. A. Freeman, Y. Shen, C.L. Werner, IEEE Transactions on geoscience and remote sensing. V. 28. No 2. Pp. 224-240 (1990)

10. S.R. Cloude, E. Pottier, IEEE Transactions on geoscience and remote sensing. V. 34. No 2. Pp. 498-518 (1996)

11. Y. Yamaguchi, A. Sato, W-M. Boerner, R. Sato, H. Yamada, IEEE Transactions on geoscience and remote sensing. V. 49. No 6. Pp. 2251-2258 (2011)

12. Patent RU 2693048. 24.04.2018. 